\title{
PENGETAHUAN DAN KETERAMPILAN PERAWAT DALAM PENGAMBILAN KEPUTUSAN KLINIS TRIASE
}

\author{
Ilfa Khairina ${ }^{\text {a*}}$; Hema Malini ${ }^{b}$; Emil Huriani c \\ a,b, c Fakultas Keperawatan Universitas Andalas \\ Jn. Kampus Limau Manis Pauh; Padang; Sumatera Barat
}

\begin{abstract}
Abstrak
Kemampuan triase yang optimal dapat diterapkan dengan baik oleh perawat yang memiliki pengetahuan dan keterampilan yang adekuat. Ketidaktepatan triase mengakibatkan ketidaefektifan tenaga kesehatan dalam memberipelayanan kesehatan sesuai dengan kondisi klisinya. Penelitian ini bertujuan menggambarkan tingkat pengetahuan dan keterampilan perawat di Instalasi Gawat Darurat (IGD) terhadap ketepatan penilaian triase. Penelitian ini merupakan penelitian kuantitatif dengan desain cross-sectional. Responden yang terlibat merupakan perawat pelaksana yang bekerja di Instalasi Gawat Darurat dengan jumlah populasi 61 perawat dan yang terlibat dijadikan sampel adalah sebanyak 54 orang yang dipilih menggunakan teknik random sampling. Pengambilan data menggunakan instrumen yaitu Triage Knowledge Questioner dan Triage Skill Questioner. Hasil penelitian didapatkan bahwa dalam aspek pengetahuan yang paling kurang dilakukan oleh perawat adalah aspek pemilihan kategori triase dengan persentase 96,3\%, dan aspek keterampilan triase perawat dalam mengalokasikan pasien berada dalam kategori cukup yaitu sebanyak $83,3 \%$. Triase yang tepat dapat membuat pasien yang membutuhkan pelayanan kesehatan melalui IGD mendapatkan perlakuan yang sesuai dengan tingkat prioritasnya. Pelatihan triase dan penggunaan modul dan algoritma dapat membuat proses triase menjadi lebih praktis, optimal dan efisien sehingga meningkatkan kualitas pelayanan dan kepuasan pasien.
\end{abstract}

Kata Kunci: Pengambilan Keputusan Klinis, Keterampilan Triase, Pengetahuan Triase , Perawat.

\begin{abstract}
[KNOWLEDGE AND NURSING SKILLS IN TRIASE CLINICAL DECISION MAKING] Triage can be applied well by nurses who have good knowledge and skills regarding triage. The inaccuracy of triage results ineffectiveness of health workers in providing health services according clinical conditions. This study aims to describe the level of triage's knowledge and skills among nurses in Emergency Department (ED). This study was descriptive with cross-sectional design. Respondents were nurses who worked in the ED with total population was 61 nurses, and used simple random sampling method, as many as 54 nurses participated in this research. Instrument of this study was a questionnaire includes Triage Knowledge Questionnaire (TKQ) and Triage Skills Questionnaire (TSQ). The results showed that aspect of knowledge which have the lack category was the selection of triage category (96,3\%), and aspect of triage's skill which have sufficient category was allocating patients $(83,3 \%)$. Triage management is to ensure that patients who need health services through ED get treatment according to their priority level. Triage training and triage modules and algorithm can make triage algorithms more easily, maintain the quality of care and patient's satisfaction.
\end{abstract}

Keyword : Clinical Decision Making, Nurses, Triage Knowledge, Triage Skill

\section{Pendahuluan}

Proses penilaian triase dilakukan untuk mengidentifikasi dan memprioritaskan pasien dalam situasi militer atau perang, bencana, dan di IGD Rumah Sakit. Penilaian triase bertujuan

\footnotetext{
*) Penulis Korespondensi (Ilfa Khairina) e-mail: ilfakhairina@nrs.unand.ac.id
}

agar pasien yang datang ke IGD mendapatkan pelayanan yang sesuai dengan kondisi klinisnya.

Australasian Triage Scale (ATS) adalah sebuah algoritma yang digunakan untuk memastikan pasien mendapatkan intervensi yang sesuai dengan waktu kritisnya (Varndell, 
et all., 2019).Triase menggabungkan keahlian klinis berbasis bukti (Garbez et al., 2011). Selain itu, triase memerlukan keterampilan klinis sesuai dengan pendekatan keperawatan gawat darurat dalam pelaksanaannya (Smith, 2013).

Pengambilan keputusan klinis mengenai triase berdasarkan kategori prioritas pasien menentukan tatalaksana asuhan keperawatan gawat darurat yang akan diterima oleh pasien. Peran triase membutuhkan keterampilan penilaian klinis yang sangat tinggi, dan dasar pengetahuan yang relevan untuk membedakan keluhan yang tidak mendesak dari kondisi yang mengancam jiwa di lingkungan pekerjaan sibuk dan membuat stres (Varndell et al., 2019). Untuk memprioritaskan pasien, pedoman triase harus direncanakan, dibuat sesuai konsep, yang terdiri dari interpretasi riwayat klinis dan informasi klinis, alokasi pasien sesuai kode urgensi, dan disposisi ke area perawatan yang sesuai dalam IGD. Faktor informasi klinis mencakup keluhan utama pasien pada saat datang ke IGD, tandatanda vital pasien, tanda dan gejala yang menyertai, dan riwayat kesehatan pasien (Garbez et al., 2011).

Sebuah studi di Amerika Serikat melaporkan bahwa dari 1 juta kejadian miokard infark sekitar 350.000 pasien meninggal di fase akut yang ditangani di IGD diakibatkan karena kerusakan otot jantung yang permanen dan bahkan kematian ketika penanganan miokard infark yang terlambat (Sanders \& DeVon, 2016). Tingkat akurasi tenaga kesehatan sangat bervariasi, mulai dari 15\%- 88\% (Varndell et al., 2019). Sekitar 50\% dari pasien yang membutuhkan perawatan di IGD mengalami ketidakakuratan dalam triase (Goldstein et al., 2017).

Keterampilan triase pada perawat IGD berfokus pada prosedur penilaian cepat, kategorisasi pasien dan alokasi pasien (Fathoni, et all., 2013). Selain menjadi keterampilan utama, triase dapat menjadi sebuat instrument untuk mengatur, memonitoring, dan mengevaluasi pasien dan sumberdaya yang ada di ED (Ahsan, et all., 2019). Ketidakakuratan triase dapat mengakibatkan hasil klinis yang buruk, lamanya waktu untuk mendiagnosa dan waktu untuk mendapatkan perawatan, ketidakefisienan dalam pemakaian sumberdaya dan fasilitas, dan bahkan meningkatkan mortalitas dan morbiditas (Ogliastri \& Zúñiga, 2016).

Perawat yang berdinas di ruang IGD adalah perawat yang memilliki sertifikasi sebagai perawat gawat dan memiliki pengalaman kerja yang baik di IGD. Saat ini, di Indonesia masih sangat kurang diketahui model perawatan triase, persiapan dan pendidikan mengenai triase di Rumah Sakit, dan proses penjaminan proses triase. Di beberapa rumah sakit di Indonesia, penilaian triase dilakukan oleh perawat yang telah memiliki pelatihan gawat darurat, dan pelatihan triase. Ketepatan penilaian triase dan capaian keselamatan pasien merupakan salah satu implikasi dari penilaian triase. Pelatihan triase, pengalaman bekerja di ruang emergensi, dan keterampilan triase merupakan faktor-faktor yang dapat mempengaruhi pengambilan keputusan klinis triase (Varndell et al., 2019).

\section{Metode}

IGD Rumah Sakit yang dipakai dalam penelitian ini adalah rumah sakit tipe $C$ yang menggunakan dan mengadaptasi pengambilan keputususan klinis triase dengan system ATS (Australian Triage Scale). Rumah Sakit Tipe C merupakan fasilitas kesehatan rujukan tingkat pertama setelah klinik pratama.

Perawat yang menjadi responden dalam penelitian ini merupakan perawat pelaksana yang bertugas di IGD. Dengan menggunakan teknik random sampling, dari populasi 61 perawat didapatkan sebanyak 54 responden dipilih secara acak dalam penelitian ini.

Penelitian ini terdaftar dan lulus uji kaji etik di Komite Etika Penelitian Fakultas Kedokteran Universitas Andalas dengan nomor 304/KEP/FK/2017. Konsep anonymity diterapkan dalam penelitian ini untuk melindungi privasi data responden

\section{Hasil dan Pembahasan}

a. Data Demografi

Dari sebanyak 54 responden didapatkan data demografi yang tertulis dalam tabel 1 , yaitu:

Tabel 1, didapatkan bahwa perbandingan antara perawat laki-laki dan perempuan hamper sebanding di IGD. Rata-rata usia perawat yang berdinas di IGD adalah 30,5 tahun dengan ratarata pengalaman bekerja selama 3,92 tahun.

Tabel 1. Data Demografi Responden 


\begin{tabular}{|c|c|c|}
\hline & $\mathrm{n}$ & $(\%)$ \\
\hline \multicolumn{3}{|l|}{ Jenis Kelamin } \\
\hline Laki-Laki & 23 & $42,6 \%$ \\
\hline Perempuan & 31 & $57,4 \%$ \\
\hline $\begin{array}{l}\text { Usia (*rata-rata usia } \\
\text { dalam tahun, SD) }\end{array}$ & $30,5^{*}$ & $3,76^{*}$ \\
\hline \multicolumn{3}{|l|}{ Tingkat Pendidikan } \\
\hline Diploma & 45 & $81,4 \%$ \\
\hline Ners & 9 & $16,6 \%$ \\
\hline $\begin{array}{l}\text { Lama Bekerja (**rata-rata } \\
\text { tahun, SD) }\end{array}$ & $3,92^{* *}$ & $2.47^{* *}$ \\
\hline
\end{tabular}

b. Pengetahuan dan Keterampilan Triase

Untuk melihat tingkat pengetahuan triase perawat dapat dilihat pada Tabel 2.

Tabel 2. Tingkat Pengetahuan Triase

\begin{tabular}{ccc}
\hline $\begin{array}{c}\text { Tingkat } \\
\text { Pengetahuan }\end{array}$ & $\mathbf{f}$ & $\mathbf{\%}$ \\
\hline Kurang & 48 & 88,89 \\
Cukup & 6 & 11,11 \\
\hline Total & $\mathbf{5 4}$ & $\mathbf{1 0 0}$ \\
\hline
\end{tabular}

Dari tabel 2, dapat dilihat bahwa sebanyak $88,89 \%$ (48 responden) memiliki tingkat pengetahuan kurang, dan sebanyak 11,11 \% (6 responden) memiliki tingkat pengetahuan cukup. Pengetahuan triase dapat dibagi menjadi 2 komponen, yaitu Pemilihan Kategori Triase, dan Skrinning Kondisi Klinis. Gambaran sebaran pengetahuan responden dapat dilihat dalam tabel 3 .

Tabel 3. Gambaran Pengetahuan Triase Responden

\begin{tabular}{lcccc}
\hline & \multicolumn{2}{c}{$\begin{array}{c}\text { Pemilihan } \\
\text { Kategori Triase }\end{array}$} & \multicolumn{2}{c}{$\begin{array}{c}\text { Skrinning } \\
\text { Kondisi Klinis }\end{array}$} \\
\hline & $\mathbf{f}$ & $\mathbf{0}$ & $\mathbf{f}$ & $\mathbf{0}$ \\
\hline Baik & 2 & 3,70 & 0 & 0 \\
Cukup & 15 & 27,7 & 2 & 3,7 \\
Kurang & 37 & 68,6 & 52 & 96,3 \\
\hline Total & $\mathbf{5 4}$ & $\mathbf{1 0 0}$ & $\mathbf{5 4}$ & $\mathbf{1 0 0}$ \\
\hline
\end{tabular}

Semua rumah sakit yang terlibat dalam penelitian ini menggunakan model adaptasi triase dengan sistem ATS. Dengan adanya sebuah sistem triase hal ini dapat mengakomodasi perawat ataupun dokter triase untuk menentukan skala triase dengan tepat. Namun hal ini harus didukung oleh pengetahuan triase yang optimal agar perawat ataupun dokter triase, sebagai penilai triase dapat menilai dengan akurat. Sebagaimana yang disampaikan oleh (Khairina, et all., 2018) bahwa tingkat pengetahuan triase merupakan faktor dominan yang berhubungan dengan pengambilan keputusan perawat dalam triase.

Triase merupakan salah satu bentuk dari proses pengambilan keputusan klinis, yang terdiri dari proses penilaian, dan memberikan prioritas kepada pasien berdasarkan kondisi klinis (Dadashzadeh, et all., 2014). Kondisi yang tidak jelas, dan keterbatasan informasi sering menjadi hambatan yang dialami perawat dan tim triase dalam menentukan skala prioritas dan tindakan penyelamatan yang diberikan selanjutnya. Oleh karena itu, menjadi penting untuk memiliki pengetahuan yang adekuat mengenai pola dan riwayat penyakit tertentu, agar perawat dan tim triase memiliki gambaran umum terhadap kondisi yang akan dihadapinya.

Tabel 4. Tingkat Keterampilan Responden

\begin{tabular}{ccc}
\hline $\begin{array}{c}\text { Tingkat } \\
\text { Pengetahuan }\end{array}$ & f & $\mathbf{\%}$ \\
\hline Cukup & 38 & 70.37 \\
Tinggi & 16 & 29.63 \\
\hline Total & $\mathbf{5 4}$ & $\mathbf{1 0 0}$ \\
\hline
\end{tabular}

Tabel 4. menunjukkan bahwa sebanyak $70,37 \%$ (38 responden) memiliki tingkat keterampilan cukup, dan sebanyak 29,63 \% (16 responden) memiliki tingkat keterampilan tinggi. Keterampilan triase dapat dibagi menjadi 3 komponen, yaitu Penilaian Cepat, Kategori Pasien, dan Alokasi Pasien. Gambaran sebaran pengetahuan responden dapat dilihat dalam tabel 4.

Tabel 5. Tingkat Keterampilan Triase

\begin{tabular}{lcccccc}
\hline & $\begin{array}{c}\text { Penilaian } \\
\text { Cepat }\end{array}$ & \multicolumn{2}{c}{$\begin{array}{c}\text { Kategori } \\
\text { Pasien }\end{array}$} & \multicolumn{2}{c}{$\begin{array}{c}\text { Alokasi } \\
\text { Pasien }\end{array}$} \\
\hline & f & $\mathbf{0}$ & $\mathbf{f}$ & $\mathbf{0}$ & $\mathbf{f}$ & $\mathbf{\%}$ \\
\hline Tinggi & 38 & 70,3 & 36 & 66,7 & 3 & 5,5 \\
Cukup & 16 & 29,7 & 18 & 33,3 & 45 & 83,3 \\
Kurang & 0 & 0 & 0 & 0 & 6 & 11,2 \\
\hline Total & $\mathbf{5 4}$ & $\mathbf{1 0 0}$ & $\mathbf{5 4}$ & $\mathbf{1 0 0}$ & $\mathbf{5 4}$ & $\mathbf{1 0 0}$ \\
\hline
\end{tabular}

Tabel 5. menunjukkan bahwa sebanyak 38 responden $(70,3 \%)$ perawat yang memiliki tingkat keterampilan tinggi, lebih memiliki keterampilan penilaian cepat dibandingkan keterampilan mengalikasikan pasien.

c. Pelatihan Gawat Darurat 
Gambaran sebaran pelatihan gawat darurat yang dimiliki oleh 54 responden dapat dilihat pada grafik 1.

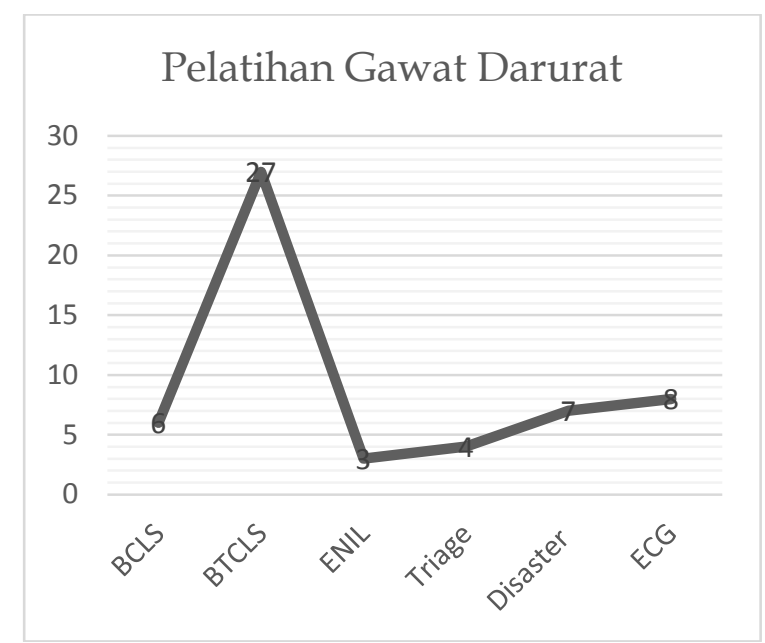

Grafik 1 sebaran pelatihan gawat darurat pada responden

Grafik 1 menunjukkan bahwa, dari sebanyak 54 perawat gawat darurat, yang memiliki pelatihan sebanyak 24 perawat, dan diantaranya yang memiliki pelatihan Basic Trauma Cardiac Life Support (BTCLS) adalah yang paling banyak.

Hasil penelitian menunjukkan bahwa dari 54 responden yang bekerja sebagai perawat triase, 4 responden sama sekali tidak memiliki pelatihan mengenai gawat darurat, dan hanya 4 perawat yang memiliki pelatihan mengenai triase. Jika dilihat dari hasil penelitian ketetapan triase, terdapat 44 responden yang tidak tepat dalam menilai skala triase, yang bisa dikategorikan ke dalam under triage dan over triage. Sistem ATS mengeluarkan pedoman pelaksanaan ATS dalam keadaan gawat darurat pada tahun 2016, dalam pedoman ini dapat ditemui kondisi-kondisi klinis apa saja yang muncul pada setiap skala triase. Misalnya kondisi klinis seperti cardiac arrest dan respiratory arrest, dengan tanda gejala yang muncul seperti adanya penurunan kesadaran dengan (Glasgow Coma Scale) GCS < 9, adanya kejang, hipoventilasi, atau adanya kondisi gangguan status mental dikelompokkan pada skala 1, dengan warna merah (Australasian College For Emergency Medicine, 2016). Jika perawat gawat darurat sudah terpapar mengenai informasi ini, resiko terhadap ketidaktepatan triase dapat diminimalisir.

d. Ketepatan skala triase
Penilaian triase dapan dibagi menjadi 3 klasifikasi yaitu under triage, over triage, dan tepat triase. Dari kuesioner yang disebar menggunakan kasus vignette, didapatkan data mengenai tingkat akurasi dalam pengambilan keputusan triase. Dari sebanyak 54 responden, dan pengambilan data dokumentasi secara retrospective didapatkan data yang tercantun dalam tabel 6.

Tabel 6. Ketepatan Triase

\begin{tabular}{lccccccc}
\hline \multirow{2}{*}{$\begin{array}{l}\text { Classificatio } \\
\mathbf{n}\end{array}$} & \multicolumn{6}{c}{ Triage Assessment } \\
\cline { 2 - 8 } & \multicolumn{2}{c}{ Inaccurate } & \multicolumn{2}{c}{ Accurate } & \multicolumn{3}{c}{ Total } \\
\cline { 2 - 8 } & $\mathbf{f}$ & $\mathbf{0}$ & $\mathbf{f}$ & $\mathbf{0}$ & $\mathbf{f}$ & $\mathbf{0}$ \\
\hline Under & 29 & 65,9 & 0 & 0 & 29 & 53,7 \\
Triage & 15 & 34,1 & 0 & 0 & 15 & 27,8 \\
$\begin{array}{l}\text { Over Triage } \\
\text { Tepat Triase }\end{array}$ & 0 & 0 & 10 & 100 & 10 & 18,5 \\
\hline Total & & & & & & \\
\hline
\end{tabular}

Tabel 6 menunjukkan bahwa lebih dari separuh $(65,9 \%)$ perawat menilai triase dengan klasifikasi under triage, dan kurang dari separuh $(34,1 \%)$ perawat yang menilai triase dengan klasifikasi over triage. 10 dari 54 (18,5\%) perawat dapat menilai triase dengan tepat.

Ketidaktepatan triase dapat mengakibatkan terjadinya menurunnya angka keselamatan pasien dan menurunnya kualitas dari layanan kesehatan tersebut (Amri, Manjas, \& Hardisman, 2019). Tingkat keramaian ruang IGD juga dapat mempengaruhi ketidaktepatan dalam triase, sehingga menjadi penting peran manajer perawat untuk dapat mengelola ruang IGD mulai dari proses rekruitmen perawat, mutasi perawat, penugasan, dan pelatihan (Odel, 2019).

Sistem evaluasi yang berkala dan berkelanjutan terhadap penilaian dan pelaksaan triase dapat menjadi salah satu cara untuk menjamin mutu pelaksanaan triase dan mendukung implementasi dari keselamatan pasien di ruang gawat darurat (Varndell et al., 2019).

Dari hasil penelian dapat dilihat bahwa dari ketidaktepatan triase, yang termasuk kategori under triage adalah yang paling banyak, yaitu sebanyak $65,9 \%$. Penilaian under triage memiliki dampak langsung ke waktu tunggu pasien, dikarenakan hal ini akan membuat waktu penanganan menjadi lebih lama dari pada kondisi klinis yang seharusnya. Ketika system triase tidak memiliki standard pelaksanaan maka waktu tunggu menjadi salah satu dampaknya (Ekins \& Morphet, 2015) 


\section{Kesimpulan dan Saran}

Pengetahuan dan pedoman mengenai triase menjadi pilar yang utama untuk mendukung pelaksanaan triase di ruang gawat darurat. Sangat dibutuhkan penyebaran informasi, sosialisasi, seminar ataupun pelatihan triase kepada perawat gawat darurat untuk menjamin pelaksaan triase berfokus pada keselataman pasien. Saat pelaksaan triase sudah sesuai dengan standar pedoman pelaksanaan triase, kualitas layanan gawat darurat menjadi lebih optimal, mengurangi memumpukkan pasien pada salah satu skala triase dan membuat waktu tunggu pasien efektif sesuai dengan kondisi klinisnya.

\section{Ucapan Terima Kasih}

Kepada seluruh responden yang terlibat dalam penelitian ini, perawat gawat darurat di Rumah Sakit Kota Padang, dan kepada Pihak Rumah Sakit yang telah memberikan izin untuk proses pengambilan data.

\section{Daftar Pustaka}

Ahsan, K. B., Karim, M. A., FitzGerald, G. J., Morel, D. G., \& Burke, J. A. (2019). Development of relationship between triaging of patients and emergency department performance. Procedia Manufacturing, 30, 200-207. https://doi.org/10.1016/j.promfg.2019.02. 029

Amri, A., Manjas, M., \& Hardisman, H. (2019). Artikel Penelitian Artikel Penelitian Analisis Implementasi Triage, Ketepatan Diagnosa Awal Dengan Lama Waktu Rawatan Pasien di RSUD Prof. DR. MA Artikel Penelitian. 8(3), 484-492.

Australasian College For Emergency Medicine. (2016). Guideline on The Implementation of The ATS. 1-8.

Dadashzadeh, A., Abdolahzadeh, F., Rahmani, A., \& Ghojazadeh, M. (2014). Factors affecting triage decision-making from the viewpoints of emergency department staff in Tabriz hospitals. 6(4), 261-266.

Ekins, K., \& Morphet, J. (2015). The accuracy and consistency of rural, remote and outpost triage nurse decision making in one Western Australia Country Health Service Region. Australasian Emergency Nursing Journal, 18(4), 227-233. https://doi.org/10.1016/j.aenj.2015.05.002
Fathoni, M., Sangchan, H., \& Songwathana, P. (2013). Relationships between Triage Knowledge, Training, Working Experiences and Triage Skills among Emergency Nurses in East Java , Indonesia. 511-525.

Garbez, A. R., Carrieri-kohlman, V., Stotts, N., Chan, G., Neighbor, M., \& Francisco, S. (2011). Factors Influencing Patient Assignment to Level 2 and Level 3 Within the 5-Level ESI Triage System. YMEN, $37(6)$,

526-532. https://doi.org/10.1016/j.jen.2010.07.010

Goldstein, L. N., Bch, M. B., Sa, F., Critical, C., Sa, C., Morrow, L. M., ... Africa, S. (2017). The accuracy of nurse performance of the triage process in a tertiary hospital emergency department in Gauteng Province, South Africa. 107(3), 243-247. https:/ / doi.org/10.7196/SAMJ.2017.v107i 3.11118

Khairina, I., Malini, H., \& Huriani, E. (2018). Faktor-Faktor yang Berhubungan dengan Pengambilan Keputusan Perawat dalam Ketepatan Triase di Kota Padang. 02(01), 1-6.

Odel, M. E. M. (2019). The Relationship Between Mindfulness, Triage accuracy, And Patient Satisfaction in The Emergency Department : A Moderation. Journal of Emergency Nursing, 45(6), 644-660. https://doi.org/10.1016/j.jen.2019.08.003

Ogliastri, E., \& Zúñiga, R. (2016). An introduction to mindfulness and sensemaking by highly reliable organizations in Latin America Journal of Business Research, 69(10), 4429-4434. https://doi.org/10.1016/j.jbusres.2016.03. 008

Sanders, S. F., \& DeVon, H. A. (2016). Accuracy in ED Triage for Symptoms of Acute Myocardial Infarction. Journal of Emergency Nursing, 42(4), 331-337. https://doi.org/10.1016/j.jen.2015.12.011

Smith, A. (2013). Using a theory to understand triage decision making. International Emergency Nursing, 21(2), 113-117. https://doi.org/10.1016/j.ienj.2012.03.003

Varndell, W., Hodge, A., \& Fry, M. (2019). Triage in Australian emergency departments: Results of a New South Wales survey. Australasian Emergency Care, 22(2), 81-86. https://doi.org/10.1016/j.auec.2019.01.003 